\title{
The Influence of Different Parameters of Magnetron Sputtering on the Structure and Chemical Composition of Titanium Alloy mplant Surfaces
}

DOI: $10,17691 / \mathrm{stm} 2019.11 .4 .14$

Received September 20, 2018

V1. Zelensky, PhD Student, Department of General and Pediatric Dentistry';

V.A. Gevorgian, PhD, Head of the Department of Materials Technology and Structure of Electronic Technique';

V.A. Tarala, PhD, Associate Professor, Department of Nanomaterials Technology3;

V.A.Zelensky, MD, DSC, Professor, Head of the Department of General and Pediatric Dentistry';

D.V. Bobryshev, MD, PhD, Head of the Center for Personalized Medicine, Scientific Innovation Centre';

E.A. Konovalov, Assistant, Department of Traumatology and Orthopedics with Continuing Professional Education Course';

M.A. Amkhadova, MD, DSc, Professor, Head of the Department of Oral Surgery and Implantology4;

S.A. Gryzunov, PhD Student, Department of Maxill-Fase Surgery5;

Al.Al. Dolgalev, MD, DSc, Associate Professor, Department of General and Pediatric Dentistry ${ }^{1}$

${ }^{1}$ Stavropol State Medical University, 310 Mira St., Stavropol, 355017, Russia;

${ }^{2}$ Russian-Armenian University, 123 Hovsep Emin St., Yerevan, 0051, Armenia;

${ }^{3}$ North-Caucasian Federal University, 1 Pushkina St., Stavropol, 355009, Russia;

${ }^{4}$ Moscow Regional Research Clinical Institute named after M.F. Vladimirskiy, 61/2-1 Schepkina St., Moscow,

129110, Russia;

5..M. Sechenov First Moscow State Medical University (Sechenov University), 8/2 Trubetskaya St., Moscow, 119991, Russia

The aim of the investigation is to study the influence of different parameters of magnetron sputtering on the structure and chemical composition of titanium and titanium alloy surfaces used for endosseous implantation.

Materials and Methods. The study involved the use of the NSC-3500 magnetron sputtering system (NANO-MASTER Inc., USA) providing the possibility to obtain coatings of almost any metals, alloys and semiconductors materials without a shift in the stoichiometric composition. High-purity argon (99.99\%) was used as the sputtering gas. A high-purity titanium (99.99\%) target was used as the source of the coating material. Polished titanium washers of Grade IV and Grade V (according to ASTM) were used as substrates for growing titanium coatings.

Titanium coatings were grown on the titanium washers at the temperature of $150^{\circ} \mathrm{C}$ and magnetron sputtering power of $200-300 \mathrm{~W}$. After obtaining the titanium coatings, the samples were heat-treated in vacuum at $450^{\circ} \mathrm{C}$ for $2 \mathrm{~h}$.

Titanium coating surface morphology was studied using atomic force microscopy on the SOLVER NEXT unit (NT-MDT, Russia).

Results and Discussion. The influence of different technological modes of deposition on the surface morphology and roughness of the obtained titanium coatings was studied. It was found that an increase in the sputtering power (from 200 to $300 \mathrm{~W}$ ) led to significant structural changes accompanied by the change in the grain size and the resulting surface roughness.

Magnetron treatment of a pure titanium sample with chemically pure titanium allows creating a nanostructured surface bonded to the substrate at the atomic level. The surface morphology varies at the nano-scale depending on the radiation power. Subsequent heat treatment $\left(a t 450^{\circ} \mathrm{C}\right)$ does not lead to significant changes in morphology, heterogeneity or granularity profile of the sample surface. When the surface of titanium aluminum-vanadium alloy Grade $\mathrm{V}$ was coated with chemically pure titanium, the elemental composition of the modified surface corresponded to the composition of titanium Grade IV (there was the complete absence of vanadium and minor aluminum impurities).

Conclusion. Magnetron sputtering of pure titanium onto implants made of titanium and titanium alloys allows obtaining high-quality nanostructured surfaces with unusual physical properties (thickness, porosity, adhesion, etc.).

Key words: endosseous titanium implants; magnetron sputtering; nanostructural morphology.

\section{Introduction}

In the last decade, restoration of organs and tissues in the human body by implantation of artificial structures (implants) has taken the lead in such areas of medicine as traumatology, oncology, neurosurgery, maxillofacial surgery, surgical dentistry.

To succeed in restoring certain parts of the skeleton, it is important to achieve osseointegration, i.e., a stable connection between the bone bed and the implant

Corresponding author: Alexander Al. Dolgalev, e-mail: dolgalev@dolgalev.pro 
surface, formed by bone cells adhering and proliferating in the implant surface or structure. The key technical factors that osseointegration depends on are the quality and structure of the implant material, the shape (design) of the implant and its surface structure. A specific approach to implantation of artificial structures is often required for patients with pre-existing chronic somatic diseases, such as diabetes mellitus, osteoporosis, and radiation therapy consequences. In these cases, the technical characteristics of implants become decisive factors for successful treatment [1].

The high-quality implant surface is the key to optimal osseointegration. Changing the micro- and nanostructure of the surface and providing it with roughness, which is achieved via nano-treatment of the contact element, makes it possible to increase its contact area. In turn, the increase in the implant surface area provides more intensive absorption of plasma proteins on the contact surface after implantation significantly increases the hydrophilic properties of the surface in contact with prosthetic bed biotissues and largely improves the osseointegration of endosseous implants.

Applying nanostructured implants in clinical practice will make implantation possible in patients with comorbidities [2].

Today, the market offers standard dental implants with the nanostructured surface, such as SLActive (Straumann, Switzerland), OsseoSpeed (Astra Tech, Sweden). These implants show a very high level of osseointegration, even in clinical situations among patients with comorbidities (diabetes, osteoporosis, etc.). A disadvantage of these constructions is the fact that these implants are standard and serve to support dental prostheses only. In addition, these implants are quite pricy [3].

Over the past 50 years, considerable experience has been gained in studying bone tissue response to implantable materials, especially in dental implantology. Unlike dental implants with almost all the surface in the bone tissue, the surface of implants for other skeleton parts contacts mostly with soft tissues. However, there are insufficient data on the soft tissue response to the metallic implant surfaces in modern literature.

Today, most endosseous implants are made of chemically pure titanium or its alloys. For this purpose, chemically pure titanium (according to ASTM international standard - Grade IV) and aluminumvanadium titanium alloy Ti-6Al-4V (according to ASTM international standard - Grade V) are used. On the one hand, aluminum and vanadium improve the strength characteristics of titanium; on the other hand, they worsen the biocompatibility of the implant. However, the cost of implants made of chemically pure titanium is higher than that of the Grade $V$ alloy due to both higher cost of the material and more expensive technology.

In the available literature, there are almost no studies of different implant coatings and their properties in relation to the type of tissue in contact with the implant surface. There are no studies on the differentiation of technologies for applying different coatings to the same implant and tissue response to the resulting surfaces.

Present-day production of endosseous and extramedullary implants is developing to manufacture personalized implants of a particular shape using 3D printing (selective laser sintering). Currently, in Russia and abroad, there has been gained certain experience in manufacturing non-resorbable plastic and metallic implants of individual shape. Experimental and clinical studies have been carried out to study the strength characteristics of these implants and biocompatibility of their materials.

In today's literature, there is evidence on the use of magnetron sputtering for the creation of biocompatible surfaces [4-6]. In Russia, this technology was developed at Tomsk Polytechnic University [7]. The work involved obtaining the calcium-phosphate coatings on implants by RF-magnetron sputtering. With this method, nanostructured films are grown on the implant surface by sputtering the target material in magnetron discharge plasma. The coatings obtained have higher purity compared to the implant surface created by sandblasting treatment and acid etching. Such treatment allows obtaining a surface with preset morphology parameters and regard for cellular response to a foreign body. Researchers have shown that high groove density of the coating reduces cell proliferation; therefore, wellordered nanopore formation is more effective in this respect. Surface modification in the range of $70-100 \mathrm{~nm}$ was found to affect the level of focal adhesion of proteins positively [8]. At present, the problem of creating implant alloy coatings with surface morphology having preset parameters and isolating the substrate materials from the body tissues is understudied in science.

The aim of the investigation is to study the influence of different magnetron sputtering parameters on the structure and chemical composition of titanium and titanium alloy surfaces used for endosseous implantation.

\section{Materials and Methods}

The source of coating material was the high-purity titanium $(99.99 \%)$ target. Magnetron sputtering was performed using the NSC-3500 system (NANO-MASTER Inc., USA). High-purity argon (99.99\%) was used as the sputtering gas. Titanium coatings were grown at the residual argon pressure of $0.001 \mathrm{~mm} \mathrm{Hg}$. The sputter deposition time was the same for all samples. Prior to the deposition process on titanium washers, the target was sputtered with the shutter closed for $10 \mathrm{~min}$ to clean the target from possible contamination. To create titanium coatings, the titanium washers were heated to $150^{\circ} \mathrm{C}$. After coating, the samples were heat-treated in vacuum at $450^{\circ} \mathrm{C}$ for $2 \mathrm{~h}$.

A total of 60 samples (30 for each grade) were examined. All of the samples were divided into 10 groups. Untreated surfaces were studied in the first two 
Table 1

Groups of titanium surface samples under study

\begin{tabular}{|c|c|c|}
\hline \multirow{2}{*}{ Deposition modes } & \multicolumn{2}{|c|}{ Surface samples } \\
\hline & Grade IV $(n=30)$ & Grade V $(n=30)$ \\
\hline Used without treatment & 6 & 6 \\
\hline $\begin{array}{l}\text { Deposited material: Ti (purity }-99.99 \% \text { ); power }-200 \mathrm{~W} \text {; treatment time - } \\
120 \text { min; substrate temperature }-150^{\circ} \mathrm{C}\end{array}$ & 6 & 6 \\
\hline $\begin{array}{l}\text { Deposited material: Ti (purity }-99.99 \% \text { ); power }-300 \mathrm{~W} \text {; treatment time - } \\
120 \text { min; substrate temperature }-150^{\circ} \mathrm{C}\end{array}$ & 6 & 6 \\
\hline $\begin{array}{l}\text { Deposited material: } \mathrm{Ti} \text { (purity }-99.99 \% \text { ); power }-200 \mathrm{~W} \text {; treatment time - } \\
120 \mathrm{~min} \text {; substrate temperature }-150^{\circ} \mathrm{C}\end{array}$ & 6 & 6 \\
\hline $\begin{array}{l}\text { Deposited material: Ti (purity }-99.99 \% \text { ); power }-300 \mathrm{~W} \text {; treatment time - } \\
120 \text { min; substrate temperature }-150^{\circ} \mathrm{C}\end{array}$ & 0 & 0 \\
\hline Preliminary vacuum annealing for $120 \mathrm{~min}$ at $450^{\circ} \mathrm{C}$ & 6 & 6 \\
\hline
\end{tabular}

groups, while 8 other groups included surfaces treated under different parameters (Table 1).

Titanium coating surface morphology was studied using atomic force microscopy on the SOLVER NEXT unit (NT-MDT, Russia) and raster electron microscopy (REM) using the scanning electron microscope MIRA 3 LMH (TESCAN, Czech Republic).

The elemental composition of the surface of samples and modified coatings was studied by energy-dispersive spectroscopy using an auxiliary device to AZtecEnergy Standard/X-max 20 microscope (TESCAN, Czech Republic).

\section{Results and Discussion}

Examination of Grade IV and Grade V samples with untreated surfaces showed: the surfaces of samples made of both Grade IV and Grade V materials were visually smooth. At 240 -fold magnification, the surface relief with concentric circles (traces of processing with
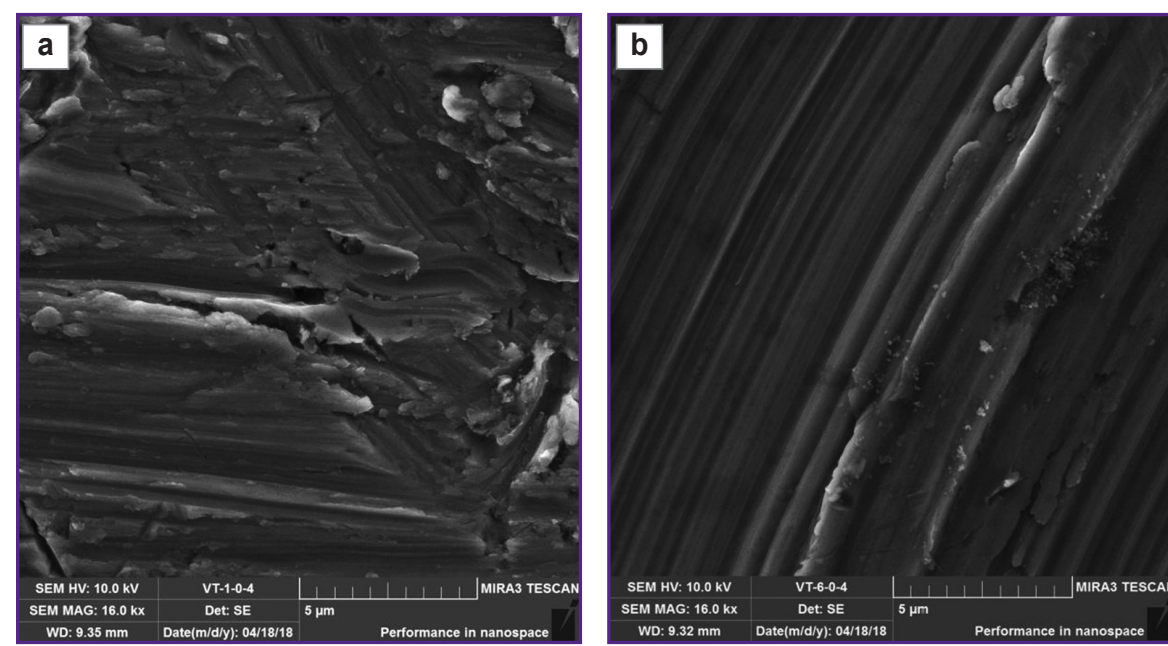

Figure 1. REM micrographs of untreated sample surface of Grade IV titanium (a) and Grade V titanium (b); $\times 16,000$ the cutting tool) was visible. At 16,000-fold magnification, surface roughness was visible (Figure 1).

The elemental analysis of samples made of Grade IV and Grade V materials prior to sputter deposition confirmed the correspondence of the claimed composition to the actual one. In particular, the following elements were found in Grade $\mathrm{V}$ samples: $\mathrm{Al}-8.69$ at. $\%, \mathrm{~V}-3.04$ at. $\%, \mathrm{Si}-0.10$ at. $\%$, $\mathrm{O}-0.87$ at. $\%, \mathrm{C}-12.12$ at. $\%, \mathrm{Ti}-75.03$ at. $\%$. In Grade IV samples, lower concentrations of impurities were revealed: $\mathrm{Al}-0.20$ at. $\%, \mathrm{Si}-0.09$ at. $\%, \mathrm{O}-$ 7.92 at. $\%, \mathrm{C}-10.11$ at. $\%, \mathrm{Ti}-81.69$ at. \% (Table 2). Increased oxygen concentrations in Grade IV samples were observed due to a higher degree of their surface oxidation as compared to Grade V samples. The elemental composition of the samples within the same group varied slightly.

The study of samples made of Grade V and Grade IV materials with modifying titanium coatings obtained via magnetron sputtering at a power of $200 \mathrm{~W}$ showed: the surfaces of samples made of both Grade IV and Grade V materials were visually smooth. At 240 -fold magnification, a uniform finegrained relief was visible. At 32,000-fold magnification, it was found that the surface of all samples was formed by particles having plate-like morphology. The particles formed agglomerates of several plates; the gaps between the plates were not detected at this magnification. The number of plates in the agglomerate varied from 3 to 10 units. The size of the agglomerates varied from $\sim 150$ to $600 \mathrm{~nm}$. The gaps between the agglomerates were 40-50 $\mathrm{nm}$. The agglomerates 
Table 2

Elemental composition of titanium item surface according to the results of energy-dispersive spectroscopy (M $\pm m$ )

\begin{tabular}{|c|c|c|c|c|c|c|c|c|}
\hline \multirow{3}{*}{$\begin{array}{l}\text { Chemical } \\
\text { elements }\end{array}$} & \multicolumn{4}{|c|}{ Grade IV sample } & \multicolumn{4}{|c|}{ Grade V sample } \\
\hline & \multicolumn{2}{|c|}{$\begin{array}{l}\text { Untreated surface } \\
\qquad(n=6)\end{array}$} & \multicolumn{2}{|c|}{$\begin{array}{c}\text { Treated surface, } \\
\text { power }-300 \text { W }(n=6)\end{array}$} & \multicolumn{2}{|c|}{$\begin{array}{l}\text { Untreated surface } \\
\qquad(n=6)\end{array}$} & \multicolumn{2}{|c|}{$\begin{array}{c}\text { Treated surface, } \\
\text { power }-300 \mathrm{~W}(n=6)\end{array}$} \\
\hline & wt. \% & at. $\%$ & wt. $\%$ & at. $\%$ & wt. \% & at. $\%$ & wt. \% & at. $\%$ \\
\hline C & $2.91 \pm 0.06$ & 10.11 & $3.78 \pm 0.10$ & 11.88 & $3.51 \pm 0.07$ & 12.12 & $4.28 \pm 0.05$ & 10.86 \\
\hline 0 & $3.04 \pm 0.15$ & 7.92 & $7.72 \pm 0.15$ & 18.22 & $0.33 \pm 0.23$ & 0.87 & $22.03 \pm 0.14$ & 41.99 \\
\hline $\mathrm{Al}$ & $0.13 \pm 0.01$ & 0.20 & $0.13 \pm 0.01$ & 0.19 & $5.65 \pm 0.03$ & 8.69 & $0.09 \pm 0.01$ & 0.10 \\
\hline $\mathrm{Si}$ & $0.06 \pm 0.01$ & 0.09 & $0.15 \pm 0.01$ & 0.20 & $0.07 \pm 0.01$ & 0.10 & $0.48 \pm 0.01$ & 0.52 \\
\hline $\mathrm{Ti}$ & $93.86 \pm 0.16$ & 81.69 & $87.99 \pm 0.17$ & 69.33 & $86.52 \pm 0.21$ & 75.03 & $73.02 \pm 0.13$ & 46.48 \\
\hline V & - & - & - & - & $3.73 \pm 0.04$ & 3.04 & - & - \\
\hline
\end{tabular}

were located on the sample surface in a random manner. When analyzing the surface structure, we saw no differences in morphology depending on the substrate material, so REM micrographs of the treated surface are given only for titanium Grade V (Figure 2).

When magnetron sputtering power was increased to $300 \mathrm{~W}$, the surface morphology of the grown titanium coatings changed. As shown by the results of studying the samples using the REM technique at 32,000 fold magnification, the coatings were formed by triangular-prismshaped nanocrystalline particles.
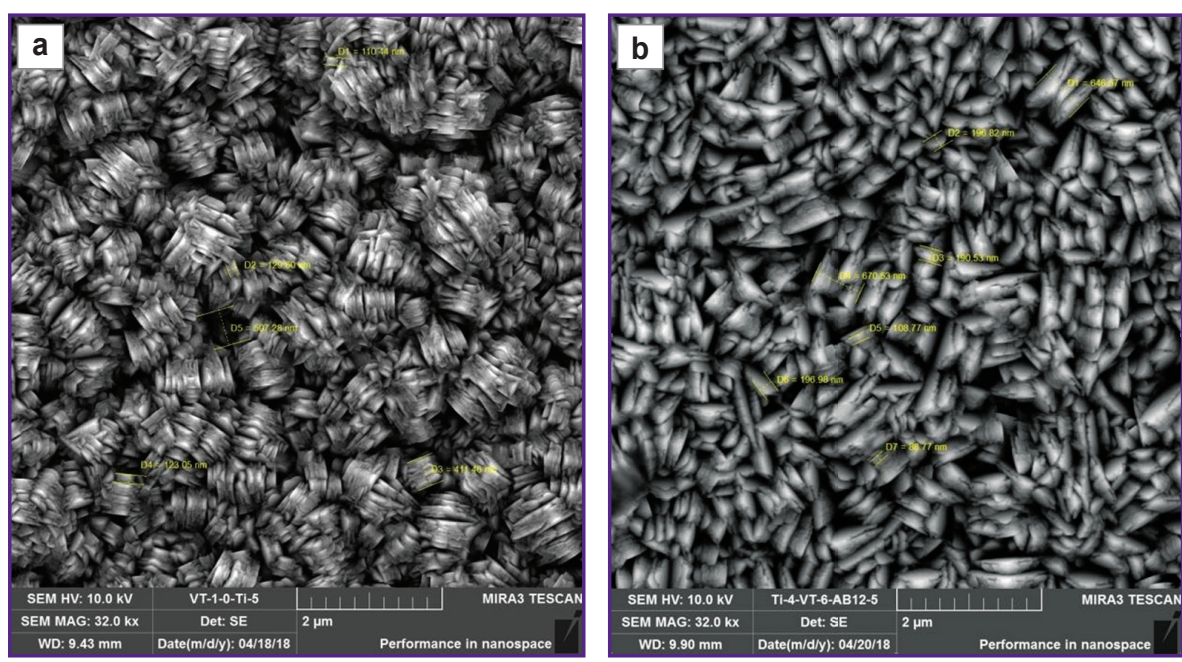

Figure 2. REM micrographs of Grade $\mathbf{V}$ titanium sample surface treated at a power of $200 \mathrm{~W}$ (a) and $300 \mathrm{~W}(\mathrm{~b}) ; \times 32,000$
The particle size was 100 to

$200 \mathrm{~nm}$. The particles were arranged in a random manner, but tightly adjacent to each other, the gaps between them were no more than 15-20 nm (see Figure 2).

The elemental analysis of coatings grown on item samples made of Grade V and Grade IV evidenced the similarity of their composition including the following elements within the error limit of the analysis method: $\mathrm{Al}-0.19$ at. $\%, \mathrm{Si}-0.20$ at. $\%, \mathrm{O}-18.22$ at. $\%, \mathrm{C}-$ 11.88 at. $\%, \mathrm{Ti}-69.33$ at. \%. We consider rather high concentrations of oxygen and carbon in the samples to be associated with the developed surface of the grown titanium layers contacting with the atmosphere after extraction of the samples from the magnetron sputtering system reactor.

The results of REM and energy dispersive spectroscopy showed:

magnetron treatment of a pure titanium item with chemically pure titanium makes it possible to create a nanostructured surface adhered to the substrate;

surface morphology at the nanoscale level differs depending on the radiation power applied;

after the magnetron treatment of titanium aluminum- vanadium alloy Grade V surface with chemically pure titanium, the elemental composition of the modified surface corresponds to that of titanium Grade IV (there is a complete absence of vanadium and minor aluminum impurities);

vacuum thermal annealing at temperatures as high as $450^{\circ} \mathrm{C}$ does not lead to noticeable changes in the coating surface morphology, heterogeneity profile, and granularity, though it significantly affects the oxygen content on the sample surface.

\section{Conclusion}

Magnetron sputter deposition of pure titanium thin-film coatings onto the surface of implants made of titanium and its alloys offers the possibility to obtain high-quality nanostructured surfaces with unusual physical properties (thickness, porosity, adhesion, etc.).

Study funding. The study was supported by the Ministry of Health of the Russian Federation, a grant as per the government task of "Development of 
nanostructured surfaces of endosseous dental implants" for 2018-2020.

Conflict of interests. The authors have no conflict of interests to disclose.

\section{References}

1. Surmeneva M.A., Surmenev R.A., Chaikina M.V., Kachaev A.A., Pichugin V.F., Epple M. Phase and elemental composition of silicon-containing hydroxyapatite-based coatings fabricated by RF-magnetron sputtering for medical implants. Inorg Mater Appl Res 2013; 4(3): 227-235, https:// doi.org/10.1134/s2075113313030131.

2. Sirin H.T., Vargel I., Kutsal T., Korkusuz P., Piskin E. $\mathrm{Ti}$ implants with nanostructured and HA-coated surfaces for improved osseointegration. Artif Cells Nanomed Biotechnol 2015; 44(3): 1023-1030, https://doi.org/10.3109/21691401. 2015.1008512.

3. Dolgalev A.A., Ivanov S.Yu., Gandylyan K.S., Zelenskiy V.A., Muraev A.A. Dental'naya implantologiya: khirurgicheskie etapy dental'noy implantatsii [Dental implantology: surgical stages of dental implantation]. Stavropol': Izd-vo StGMU; 2018.
4. Song Y.-H., Cho S.-J., Jung C.-K., Bae I.-S., Boo J.-H., Kim S. The structural and mechanical properties of Ti films fabricated by using RF magnetron sputtering. J Korean Phys Soc 2007; 51(3): 1152, https://doi.org/10.3938/jkps. 51.1152.

5. Arshi N., Lu J., Lee C.G., Yoon J.H., Koo B.H., Ahmed F. Thickness effect on properties of titanium film deposited by d.c. magnetron sputtering and electron beam evaporation techniques. Bull Mater Sci 2013; 36(5): 807-812, https://doi. org/10.1007/s12034-013-0552-2.

6. Chawla V., Jayaganthan R., Chawla A.K., Chandra R. Microstructural characterizations of magnetron sputtered $\mathrm{Ti}$ films on glass substrate. J Mater Process Technol 2009; 209(7): 3444-3451, https://doi.org/10.1016/j.jmatprotec.2008.08.004.

7. Tverdokhlebov S.I., Shesterikov E.V., Mal'chikhina A.I. Features of the formation of calcium-phosphate coatings by high-frequency magnetron sputtering on implants. Izvestiya Tomskogo politekhnicheskogo universiteta 2012; 320(2): 73-79.

8. Deogade S.C., Dube G., Sumathi K., Dube P., Katare U., Katare D., Damade S. Current status of nanotechnology methods applied for dental implants. International Journal of Pharmaceutical Science Invention 2015; 4(7): 32-43. 